\title{
ANATOMICAL VARIATIONS OF ANTERIOR CIRCULATION IN THE BRAINS OF PATIENTS WITH AND WITHOUT INTRACRANIAL ANEURYSM
}

\author{
Ali YILMAZ*, Ayça ÖZKUL** \\ *Adnan Menderes University Faculty of Medicine, Department of Neurosurgery, Aydın, TURKEY \\ ** Adnan Menderes University Faculty of Medicine, Department of Neurology, Aydın, TURKEY
}

\begin{abstract}
INTRODUCTION: Anatomic variations of cerebral arteries may influence the development of aneurysms. In this study our aim was to determine vascular anatomical variations of the anterior circulation of the brain in patients with and without cerebral aneurysms and also the relationship between vascular variations.

METHODS: The cerebral digital subtraction angiography data of 438 patients were investigated retrospectively. Anatomical vascular variations of MCA and ACA-AcomA complex were investigated separately in patients with and without aneurysm.

RESULTS: Most of our patients with cerebral aneurysms had SAH (n: 68, 80\%). Although normal ACA AcomA complex and MCA vascular anatomy was less frequently seen in SAH, there was no statistical significance. ACA AcomA vascular anatomy was not significantly different between patients with and without cerebral aneurysm, however patients with cerebral aneurysm had statistically higher MCA vascular anatomical variations (p: 0.03).

DISCUSSION and CONCLUSION: ACA-AcomA vascular anatomy was not significantly different between patients with and without cerebral aneurysm. However MCA vascular anatomical variations were more commonly seen in patients with cerebral aneurysm. Variations of MCA may increase the risk of aneurysm formation and therefore have an important role in the planning of aneurysm treatment.
\end{abstract}

Keywords: Aneurysm, cerebral artery, variation.

\section{INTRAKRANIAL ANEVRIZMASI OLAN VE OLMAYAN HASTALARIN BEYINLERINDEKİ ANTERIOR DOLAȘIMIN ANATOMIK VARYASYONLARI}

\section{ÖZET}

GİRIŞ ve AMAÇ: Serebral arterlerin anatomik varyasyonları anevrizmaların gelişimini etkileyebilir. Bu çalışmada amacımız serebral anevrizmalar bulunan ve bulunmayan hastalarda beyin anterior dolaşımının vasküler anatomik varyasyonlarını ve vasküler varyasyonlar arasındaki ilişkiyi saptamaktır.

YÖNTEM ve GEREÇLER: 438 hastanın serebral digital subtraction anjiyografi verileri retrospektif olarak incelendi. Anevrizma olan ve olmayan hastalarda MCA ve ACA-AcomA kompleksinin anatomik vasküler varyasyonları ayrı ayrı incelendi.

BULGULAR: Serebral anevrizma hastalarının çoğunda SAH vardı (n: 68,\% 80). SAAH'da normal ACA AcomA kompleksi ve MCA vasküler anatomisi daha az görüldü ancak istatistiksel olarak anlamlı bir fark yoktu. ACA AcomA vasküler anatomisi, serebral anevrizması olan ve olmayan hastalar arasında anlamlı farklılık göstermedi; ancak serebral anevrizma hastalarında istatistiksel olarak daha yüksek MCA vasküler anatomik varyasyonları vardı (p: 0.03).

TARTIȘMA ve SONUC: ACA-AcomA vasküler anatomisi serebral anevrizması olan ve olmayan hastalar arasında anlamlı farklılık göstermedi. Ancak MCA vasküler anatomik varyasyonları serebral anevrizması olan hastalarda daha sık görüldü. MCA varyasyonları anevrizma olușma riskini artırabilir ve bu nedenle anevrizma tedavisinin planlanmasında önemli bir role sahiptir.

Anahtar Sözcükler: Anevrizma, beyin arteri, varyasyon.

Corresponding author: Ali Ylmaz Assoc. Prof. MD. Adnan Menderes University, Faculty of Medicine, Department of Neurosurgery, Aydın, Turkey. Telephone: +904441256 E-mail: dryilmazali@gmail.com

Received: $15.01 .2018 \quad$ Accepted: 06.02.2018

This article should be cited as following: Yllmaz A, Özkul A. Anatomical variations of anterior circulation in the brains of patients with and without intracranial aneurysm. Turkish Journal of Cerebrovascular Diseases 2018; 24 (1): 8-13. doi:10.5505/tbdhd.2018.54154 


\section{INTRODUCTION}

The anatomy of the cerebral arterial system can influence the development of arterial diseases such as aneurysms, dolichoectasia, hemorrhage and even atherosclerosis. These variations may also affect the prognosis and treatment of such vascular diseases, especially aneurysmal subarachnoid hemorrhage (SAH). Intracranial aneurysms may cause subarachnoid hemorrhage, which is a serious health problem with high mortality and morbidity, and they affect approximately $2 \%-5 \%$ of the population (1). Aneurysm appears as a result of a weakness of the walls of a blood vessel, which causes a specific point of the vessel to be thinner and to tend to rupture due to the pressure inside. However not all aneurysms bleed. With the development of neuroimaging technology, a large number of unruptured aneurysms, which may affect from $2 \%$ to $10 \%$ of the general population, have been discovered $(1,2)$. The incidence of $\mathrm{SAH}$ is relatively low, with an annual rupture rate of approximately $1 \%-2 \%$ per year (1). The treatment options, including surgical clipping or endovascular coiling, are associated with risks, and cerebral hemodyamic changes should be evaluated preoperatively. Therefore, anatomical variations of vessels are important for decisions on treatment. The aim of this study is to identify the relationship between the vascular anatomical variations of the anterior cerebral circulation complex (anterior cerebral artery-anterior communicating artery (ACA-AcomA) and middle cerebral artery (MCA)) in patients with and without cerebral aneurysms, and also SAH.

\section{MATERIAL AND METHODS}

This study included 438 cerebrovascular patients who underwent cerebral digital subtraction angiography (DSA) in our Neurosurgery Department between February 2015 and May 2017. This was a retrospective study which was approved by the local ethics committee of our university. The patients were diagnosed as having SAH according to noninvasive neuroimaging examination including computed tomography (CT), magnetic resonance imaging (MRI), CT angiography, and MR angiography. The cerebral DSA procedures were performed in the angiography suite by an endovascular specialist to investigate cerebral aneurysm within 2-48 hours (mean $5.8 \pm 1.93 \mathrm{~h}$ ) of admission. DSA images of each patient and the detailed reports were analyzed retrospectively by a neurosurgeon who practiced neurovascular surgery. The patients were studied as aneurysmal, nonaneurysmal as well as subjects with and without SAH. The cerebral aneurysms were divided into six subgroups according to their localizations including ACA, MCA, AcomA, internal carotid, posterior circulation aneurysms and multiple aneurysms. Anatomical vascular variations of the ACA, AcomA, and MCA arterial system were grouped and studied morphologically: ACAAComA complexes were classified into 10 types: typical configuration (type1); hypoplastic ACoA (type 2), aplastic AComA (type 3), unilateral A1 ACA segment hypoplasia (type 4), unilateral A1 ACA segment aplasia (type5), common trunk of ACA with absence of AComA (type6), presence of a third A2 ACA segment (median artery of the corpus callosum) (type 7), unilateral hypoplasia of A1 ACA segment and A2 ACA segment (bihemispheric ACA) (type8), unilateral A2 ACA segment aplasia (azygos ACA) (type9), and duplicated AComA (type 10). All described types can be seen schematized in Figure I.

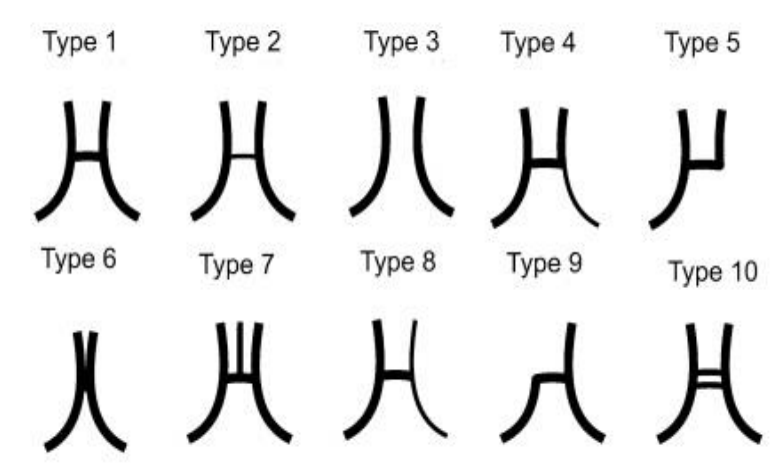

Figure I. ACA-AComA vascular variaitons were classified into 10 types: typical configuration (type1); hypoplastic ACoA (type 2), aplastic AComA (type 3), unilateral A1 ACA segment hypoplasia (type 4), unilateral A1 ACA segment aplasia (type5), common trunk of ACA with absence of AComA (type6), presence of a third A2 ACA segment (median artery of the corpus callosum) (type 7), unilateral hypoplasia of A1 ACA segment and A2 ACA segment (bihemispheric ACA) (type8), unilateral A2 ACA segment aplasia (azygos ACA) (type9) and duplicated AComA (type 10) (3). 
Vascular variants of middle cerebral arteries include normal MCA with superior and inferior branches (type 1), accessory MCA (type 2), duplicating MCA (type 3) and fenestrations of MCA (type 4) (Figure II).

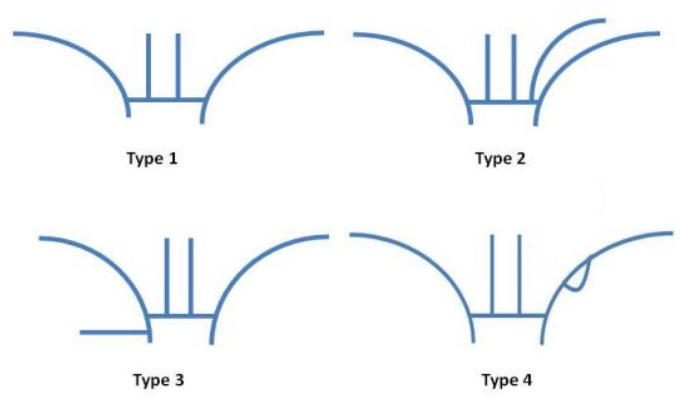

Figure II. Normal MCA with superior and inferior branches (type 1), accessory MCA (type 2), duplicating MCA (type 3) and fenestrations of MCA (type 4).

\section{Statistical Analyses}

All statistical analyses were performed using SPSS 16.0 for Windows (SPSS Inc., Chicago, IL). Group comparisons were performed using statistical methods. We used the Pearson ChiSquare test to compare qualitative data and the Student t-test to compare continuous variables. $p$ values of less than 0.05 were considered to indicate statistical significance.

\section{RESULTS}

A total of 438 patients (158 females and 280 males) with a mean age of $60.0 \pm 16.05$ (20-89) years were included in the study. The patients were classified as aneurysmal (n:85, 19.4\%), nonaneurysmal (n:353, 80.6\%) and also with (n:91, 20.7\%) and without SAH (n:347, 79.2\%). The demographic characteristics of patients are shown in Table I. The cerebral aneurysms were evaluated according to their localizations and were evaluated in six subgroups. Most of them were located in AComA (n:37, 43.5\%). The others were located as follows: MCA (n:24, 28.2\%), ICA (n:10, $11.76 \%)$, ACA (n:4, 4.7\%), posterior circulation aneurysms (n:12, 14.12\%) and multiple aneurysms (n:6, 7.05\%). There were no significant differences between these six subgroups with respect to age and gender. Most of our patients with cerebral aneurysms had SAH (n:68, 80\%). MCA and ACA-AcomA complex variations were investigated separately in patients with and without SAH. Although normal ACA and MCA vascular anatomy was less frequently seen in SAH, there was no statistical significance. In addition to this result, ACA vascular anatomy was not significantly different between patients with and without cerebral aneurysm. On the other hand, patients with cerebral aneurysm had statistically higher MCA vascular anatomical variations (p:0.03) (Table II and Table III).

We also compared patients with MCA aneurysm and patients without any vascular pathology but couldn't find any statistical difference in MCA types between these groups. Our data also showed that there is no relationship between presence of AComA aneurysm and ACAAcomA complex vascular variation (Table IV).

Table I. The demographic and clinical data of the patients.

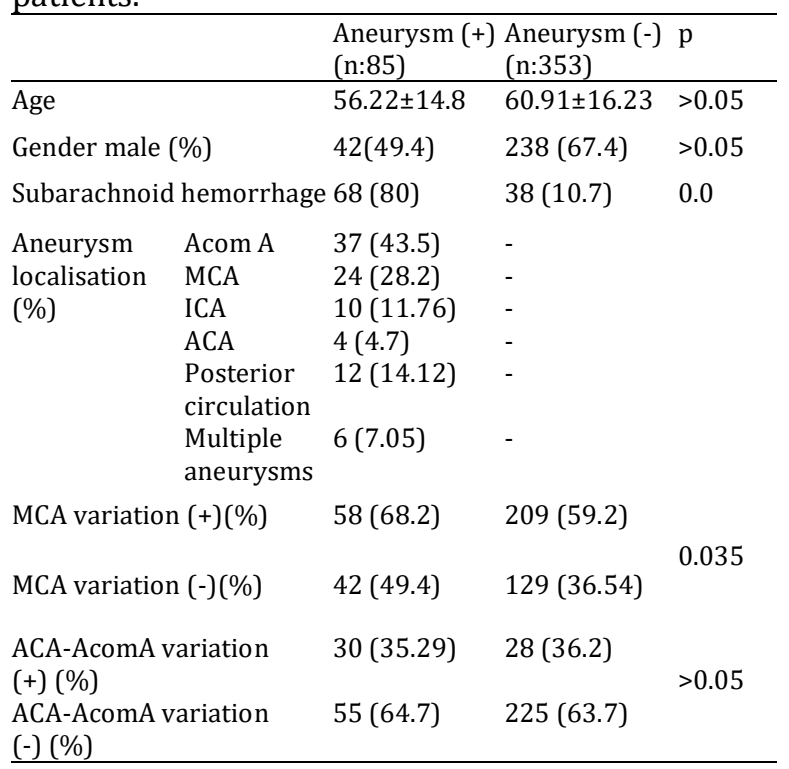

Table II. Variants of the ACA-AcomA complex and MCA in patients with and without SAH.

\begin{tabular}{llll}
\hline & SAH(+) & SAH(-) & $p$ \\
\hline MCA variation (+) & $49(53.8)$ & $218(62.8)$ & $>0.05$ \\
MCA variation (-) & $42(46.15)$ & $129(37.1)$ & $>0.05$ \\
ACA-AcomA variation (+) & $27(29.67)$ & $131(37.7)$ & $>0.05$ \\
ACA-AcomA variation (-) & $64(70.3)$ & $216(62,27)$ & $>0.05$ \\
\hline
\end{tabular}

Turkish Journal of Cerebrovascular Diseases 2018; 24 (1): 8-13 
Table III. Prevalence of classified variants of the ACA-AcomA complex and MCA.

\begin{tabular}{llll}
$\begin{array}{l}\text { MCA variation } \\
\text { type }\end{array}$ & $\mathrm{n}(\%)$ & $\begin{array}{l}\text { ACA-AcomA } \\
\text { variation type }\end{array}$ & $\mathrm{n}(\%)$ \\
\hline 1 & $327(74.6)$ & 1 & $201(45.8)$ \\
2 & $72(16.4)$ & 2 & $105(23.9)$ \\
3 & $29(6.6)$ & 3 & $29(6.6)$ \\
4 & $10(2.2)$ & 4 & $39(8.9)$ \\
& & 5 & $32(7.3)$ \\
& & 6 & $6(1.4)$ \\
& & 7 & $2(0.5)$ \\
& & 8 & $18(4.1)$ \\
& & 9 & $4(1.4)$ \\
& & 10 & $2(1.4)$
\end{tabular}

ACA-AcomA variation type: typical configuration (type1); hypoplastic ACoA (type 2), aplastic AComA (type 3), unilateral A1 ACA segment hypoplasia (type 4), unilateral A1 ACA segment aplasia (type5), common trunk of ACA with absence of AComA (type6), presence of a third A2 ACA segment (median artery of the corpus callosum) (type 7), unilateral hypoplasia of A1 ACA segment and A2 ACA segment (bihemispheric ACA) (type8), unilateral A2 ACA segment aplasia (azygos ACA) (type9),and duplicated AComA (type 10)

MCA variation type: normal MCA with superior and inferior branches (type 1), accessory MCA (type 2), duplicating MCA (type 3) and fenestrations of MCA (type 4)

Table IV. Variants of the ACA-AcomA complex and MCA in aneurysm presence.

\begin{tabular}{llll}
\hline & $\begin{array}{l}\text { MCA aneurysm } \\
(+)\end{array}$ & $\begin{array}{l}\text { Cerebral aneurysm } \\
(-)\end{array}$ & $p$ \\
\hline $\begin{array}{l}\text { MCA variation } \\
(+)\end{array}$ & $12(5.08)$ & $129(37.1)$ & $>0.05$ \\
$\begin{array}{l}\text { MCA variation } \\
(-)\end{array}$ & $12(8.5)$ & $224(91.4)$ & \\
\hline \multicolumn{5}{c}{$\begin{array}{l}\text { AComA aneurysm Cerebral aneurysm } \\
(+)\end{array}$} & $\begin{array}{l} \\
\text { ACA-AcomA } \\
\text { variation }(+)\end{array}$ & $13(9.2)$ & $128(91.4)$ & $>0.05$ \\
$\begin{array}{l}\text { ACA-AcomA } \\
\text { variation }(-)\end{array}$ & $24(9.6)$ & $225(90.3)$ & $>0.05$ \\
\hline
\end{tabular}

\section{DISCUSSION}

In this study we examined the anatomical variations of the anterior circulation of the brain. Our aim was to determine vascular anatomical variations of the anterior circulation of the brain in patients with and without cerebral aneurysms and also to identify the relationship between vascular variations and SAH. Although ACA vascular anatomy was not significantly different between aneurysmal and nonaneurysmal patients, we found that MCA variations were more frequently accompanied by cerebral aneurysm.

The typical configuration of ACA-AcomA complex was seen only in $36.1 \%$ of all subjects.
This frequency was similar in patients both with and without aneurysm $(35.3 \%$ vs $36.3 \%$, p $>0.05)$. In the literature, the frequency of normal vascularity was found to be $52.55 \%(\mathrm{n}: 411)$ in a study including only normal subjects. (3). There is also another study with data reporting that normal ACA-AcomA variation was seen in $63.3 \%$ (n:128) of patients with cerebral aneurysm (4). In another study, a lower incidence of a typical ACoA complex anatomy and a higher frequency of hypoplastic or aplastic arteries (36\% vs. 9\%; $p<0.01$ ) were found in patients with AcomA aneurysm (5). There was also a strong statistical association between unilateral A1 ACA segment hypoplasia and the presence of an $\mathrm{ACoA}$ aneurysm $(24 \%$ vs $7 \%$; $\mathrm{p}<0.01$ ) (6).

We found a lower frequency of normal anatomical variation of anterior circulation. Both aneurysmal and nonaneurysmal patients had similar frequencies and there was no statistical significance. This discrepancy with the literature may depend on different study designs as well as on anatomical variations in different populations.

The most common anomaly of the ACAAcomA complex was hypoplastic AcomA, and this was more prevalent in females (7). In cadaveric studies, the frequency of AComA hypoplasia was reported as 9.15 to $30 \%(7,8)$. Aplastic AComA was rare and found only in $1.8 \%$ of autopsies (9). In a recent neuroradiology study, aplastic AcomA was seen at $9.38 \%$ in the CTA of normal Chinese people (11). In our study, we found hypoplastic AcomA at $33.78 \%$, which is higher than the data mentioned. Additionally, the frequency of this variation showed no difference between aneurysmal and nonaneurysmal subjects. Aplastic AcomA was found in $6.6 \%$ of our patients, which is quite similar to the Chinese study. However, the differences in study methods and groups enable accurate comparison of all these data.

We also investigated the frequency of hypoplasia (8.9\%) and aplasia (7.3\%) of the unilateral A1 ACA segment. Unilateral hypoplasia of the A1 ACA segment and the A2 ACA segment (bihemispheric ACA) had a frequency of $4.1 \%$. In total, A1 ACA segment variations were detected in $20.3 \%$ of patients. There was no association between A1 ACA segment hypoplasia or aplasia and the presence of an aneurysm. In the literature, the frequency of A1 segment anomalies was reported to be $36 \%$ (11). In a similar study of the Polish population, the frequency of A1 segment anomalies in aneurysm patients was $37.7 \%$ (12). 
Association between the presence of an A1 segment aplasia or hypoplasia and the presence of an AComA aneurysm has been shown in literature. Castro et al. (5) showed that an asymmetric A1 artery blood inflow had an effect on AComA aneurysm formation and rupture. An aplastic or hypoplastic A1 segment of ACA can be considered to be a risk factor for aneurysm formation since this is a common finding in patients with ACoA aneurysms (13). The frequency of A1 segment hypoplasia in patients without aneurysms ranges between 4.76 and $8.4 \%$ (3), and was $8.9 \%$ in our study. We also found the frequency of aplasia of the $\mathrm{A} 1$ segment to be $7.3 \%$, and this is compatible with the literature $(1.86-8.0 \%)$ (3). There is a diversity among such studies. This may result from various definitions, methods and confounding factors. It is worth noting that Eftekhar et al found no significant differences in the distribution of cerebral arterial anomalies in different populations (22).

Vascular variations are more frequently seen in other cerebral arteries than in the MCA, including duplicated MCA, accessory MCA, early branching of middle cerebral arteries and fenestrations (15). The accessory MCA arises from the A1 segment of the ACA $(15,16)$. The duplicated MCA usually supplies the temporal lobe $(15,17)$.

The accessory MCA was seen at about 0.4 (18) and it was more frequently detected in postmortem examinations (3\%) (19). In the literature it varies between 0.3 and $4.0 \%(18,20)$. In our study, accessory MCA was detected in $16.4 \%$ of our patients. This is a higher value than in the literature. Additionally, patients with aneurysm had a higher frequency of vascular variation, and the most common seen variation was found to be accessory MCA. There are reports of association between these lesions and the formation of brain aneurysms, particularly in a branch in the A1 segment $(18,20)$. However, we found no relationship between the presence of aneurysm and accessory MCA. The second most common variation of MCA was duplicated MCA which was present in $0.3 \%$ to $7.1 \%$ of cases in the literature (15). In our study, 3\% of all subjects had duplicated MCA and this variation did not differ between groups with and without aneurysm.

We also examined whether there was a relationship between MCA variation and the presence of aneurysm. Patients with cerebral aneurysm had statistically more MCA vascular anatomical variations. However, there is limited data about this relationship in the literature. Orakdogen $\mathrm{M}$ et al. showed that MCA variation rate and aneurysm coexistence showed no statistically significant difference in any localization (4).

Additionally, there was no relationship between aneurysmal SAH and the presence of arterial variations in our study, although it was shown in one study that vascular variations are more common in bleeding aneurysms (61.3\% versus $40.9 \%$ ) (4). In our study however, the presence of vascular variations was not related to aneurysmal SAH.

There are limitations in our study. First of all different study designs and ethnic groups may cause this discrepancy of data in literature. Secondly, we analyzed the initial cerabral DSA which may not show aneurysms due to cerebral vasospasm. Differences in the distribution of cerebral arterial anomalies in different populations need to be evaulated in larger series.

As conclusion, we studied the relationship between the vascular anatomical variations of anterior cerebral circulation in patients with and without cerebral aneurysms. Although ACAAcomA complex and MCA normal vascular anatomy were less frequently seen in SAH, there was no statistical significance. There was no association between aneurysm localization and vascular variations either. Our data suggested that ACA-AcomA vascular anatomy was not significantly different between patients with and without cerebral aneurysm. On the other hand, MCA vascular anatomical variations were more commonly seen in patients with cerebral aneurysm. Variations of MCA may increase the risk of aneurysm formation and therefore have an important role in the planning of aneurysm treatment. The actual prevalence of such anomalies may differ in different populations, and this needs further studies. Awareness of these variations would guide the choice and application of treatment modalities, and increase the success rate in managing patients.

\section{REFERENCES}

1. Cai W, Shi D, Gong J, Chen G, Qiao F, Dou X, Li H, Lu K, Yuan S, Sun C, Lan Q.Are Morphologic Parameters Actually Correlated with the Rupture Status of Anterior Communicating Artery Aneurysms? World Neurosurg. 2015Nov;84(5):1278-83.doi: 10.1016/j.wneu.2015.05.060.

2. Nader-Sepahi A, Casimiro M, Sen J, Kitchen ND. Is aspect ratio a reliable predictor of intracranial aneurysm rupture? Neurosurgery. 2004 Jun;54(6): 1343-7. 
3. Krzyżewski RM, Tomaszewski KA, Kochana M, Kopeć M, Klimek-Piotrowska W,Walocha JA. Anatomical variations of the anterior communicating artery complex:gender relationship. Surg Radiol Anat. 2015 Jan;37(1):81-6. doi:10.1007/s00276-014-1313-7. Epub 2014 May 22.

4. Orakdogen M, Emon ST, Somay H, Engin T, Iș M, Hakan T. Vascular VariationsAs sociated with Intracranial Aneurysms. Turk Neurosurg. 2016 May 25. doi:10.5137/1019-5149.JTN.17839-16.1.

5. Castro MA, Putman CM, Sheridan MJ, Cebral JR Hemodynamic patterns of anterior communicating artery aneurysms: a possible association with rupture. AJNR Am J Neuroradiol 2009; 30: 297-302.

6. Charbel FT, Seyfried D, Mehta B, Dujovny M, Ausman JI. Dominant A1: angiographic and clinical correlations with anterior communicating artery aneurysms. Neurol Res 1991; 13: 253-256.

7. El Khamlichi A, Azouzi M, Bellakhdar F, Ouhcein A, Lahlaidi A. Anatomic configuration of the circle of Willis in the adult studied by injection technics. Apropos of 100 brains. Neurochirurgie 1985; 31: 287-293.

8. Krupa B, Krupa U. Variations of the anterior communicating artery. Folia Morphol (Warsz) 1998,57:233-240.

9. Kapoor K, Singh B, Dewan LI. Variations in the configuration of the circle of Willis. Anat Sci Int 2008;83:96-106.

10. Li Q, Li J, Lv F, Li K, Luo T, Xie P. A multidetector CT angiography study of variations in the circle of Willis in a Chinese population. J Clin Neurosci 2011; 18: 379-383.

11. Krzyzewski RM, Tomaszewska IM, Lorenc N, Kochana M, Goncerz G,Klimek-Piotrowska W, Walocha K, Urbanik A. Variations of the anteriorcommunicating artery complex and occurrence of anterior communicating artery aneurysm: A2 segment consideration. Folia Med Cracov. 2014; 54(1): 13-20.
12. Klimek-Piotrowska W., Kopeć M., Kochana M., et al.Configurations of the circle of Willis: a computed tomography angiography based study on a Polish population. Folia Morphol (Warsz). 2013; 72: 293-299.

13. Charbel FT, Seyfried D, Mehta B, Dujovny M, Ausman JI Dominant A1: angiographic and clinical correlations with anterior communicating artery aneurysms. Neurol Res 1991; 13: 253-256.

14. Eftekhar B., Dadmehr M., Ansari S., Ghodsi M., Nazparvar B., Ketabchi E.: Are the distributions of variations of circle of Willis different in different populations? - Results of an anatomical study and review of literature. BMC Neurol. 2006; 24: 6-22.

15. Cilliers K, Page BJ. Anatomy of the Middle Cerebral Artery: Cortical Branches,Branching Pattern and Anomalies. Turk Neurosurg. 2017; 27(5): 671-681.

16. Komiyama M, Nishikawa M, Yasui T: The accessory middle cerebral artery as a collateral blood supply. AJNR Am J Neuroradiol 1997; 18: 587-590.

17. Chang HY, Kim MS. Middle cerebral artery duplication : classification and clinical implications. J Korean Neurosurg Soc. 2011 Feb; 49(2): 102-6.

18. Komiyama $M$, Nakajima $H$, Nishikawa $M$ et al: Middle cerebral artery variations: duplicated and accessory arteries. Am J Neuroradiol, 1998; 19: 45-49.

19. Jain KK: Some observations on the anatomy of the middle cerebralartery. Can J Surg, 1964; 7: 134-39.

20. Otani N, Nawashiro $\mathrm{H}$, Tsuzuki $\mathrm{N}$ et al: A ruptured internal carotid artery aneurysm located at the origin of the duplicated middle cerebral artery associated with accessory middle cerebral artery and middle cerebral artery aplasia. Surg Neurol Int, 2010; 1: 51. 